\title{
Long-Term Results after Glycerol Rhizotomy for Multiple Sclerosis-Related Trigeminal Neuralgia
}

\author{
Douglas Kondziolka, L. Dade Lunsford and David J. Bissonette
}

\begin{abstract}
Percutaneous retrogasserian glycerol rhizotomy (PRGR) was used during an 11 -year interval in 53 patients with typical trigeminal neuralgia associated with multiple sclerosis. All patients had failed extensive medical trials prior to PRGR. Long-term (median follow-up, 36 months) complete pain relief (no further medication) was achieved in 29 (59\%) of 49 evaluable patients. Eight patients (16\%) had satisfactory pain control but required occasional medication. Twelve patients (25\%) had initial unsatisfactory results with inadequate pain relief; nine underwent alternative surgical procedures. Sixteen patients $(30 \%)$ subsequently required repeat glycerol rhizotomies to reachieve pain control. Twenty-seven patients ( $60 \%$ of 45 patients evaluated for this finding) retained normal trigeminal sensation after injection. Major trigeminal sensory loss developed in a single patient who had four glycerol rhizotomies over a 25 -month interval. No patient developed deafferentation pain. We believe that PRGR is a low-morbidity, effective, and repeatable surgical procedure for the management of trigeminal neuralgia in the setting of multiple sclerosis.
\end{abstract}

\begin{abstract}
Résumé: Résultats à long terme de la rhizotomie au glycerol comme traitement de la névralgie du trijumeau dans la sclérose en plaques. La rhizotomie percutanée rétrogassérienne au glycérol (RPRG) a été utilisée pendant une période de 11 ans chez 53 patients avec une névralgie du trijumeau typique associée à une sclérose en plaques. Chez tous les patients, tous les traitements médicaux avaient échoué antérieurement. Un soulagement complet de la douleur (aucune médication) à long terme (suivi médian de 36 mois) a été obtenu chez 29 (59\%) des 49 patients qu'on a pu évaluer. Huit patients (16\%) ont obtenu un contrôle satisfaisant de la douleur, mais ont eu besoin occasionnellement d'une medication. Douze patients $(25 \%)$ ont eu un resultat insatisfaisant initialement; neuf ont subi d'autres manoeuvres chirurgicales. Seize patients (30\%) ont eu besoin d'une nouvelle rhizotomie au glycérol pour contrôler la douleur. Vingt-sept patients $(60 \%)$ des 45 patients évalués pour ce critère ont conservé une perception sensitive normale au niveau du trijumeau après l'injection. Un seul patient, qui avait subi quatre rhizotomies au glycérol sur une période de 25 mois, a développé un déficit sensitif majeur. Aucun patient n’a développé de douleur de désafférentiation. Nous pensons que la RPRG est une manoeuvre chirurgicale efficace, qui a un taux de morbidité bas et qui peut être répétée, pour le traitement de la névralgie du trijumeau, chez les patients porteurs d'une sclérose en plaques.
\end{abstract}

Can. J. Neurol. Sci. 1994; 21: 137-140

Approximately two percent of patients with multiple sclerosis develop trigeminal neuralgia. The etiology of facial pain in such patients may be related to the development of demyelinating plaques at the trigeminal-root entry zone, in the descending trigeminal tracts, or in the brainstem nuclei. ${ }^{1}$ In the context of multiple sclerosis, operations such as microvascular decompression $^{2}$ have a reduced role. For multiple sclerosis trigeminal neuralgia patients who are refractory to medication regimens, percutaneous trigeminal operations have been advocated. They include retrogasserian glycerol rhizotomy, ${ }^{3}$ radiofrequency thermal rhizotomy, ${ }^{1,4}$ and inflatable balloon compression. ${ }^{5}$ In the present study we retrospectively analyzed the long-term efficacy of PRGR in the management of multiple sclerosis-related trigeminal neuralgia.

\section{Material and Methods}

\section{Patient Population}

Percutaneous glycerol rhizotomies were initially performed in 53 patients ( 35 females, 18 males, median age 56 years). Two patients later had an additional procedure on the contralateral side for bilateral pain. These patients represented a subset of 594 patients who had this procedure for trigeminal neuralgia

From the Department of Neurological Surgery, University of Pittsburgh and the Specialized Neurosurgical Center, Presbyterian University Hospital, University of Pittsburgh, Pittsburgh.

RECEIVED OCTOBER 20, 1993. ACCEPTED IN FINAL FORM JANUARY 14, 1994

Reprint requests to: Douglas Kondziolka, M.D., Department of Neurological Surgery, B-400 Presbyterian University Hospital. University of Pittsburgh, Pittsburgh, Pennsylvania, U.S.A. 15213 
during an eleven year interval from 1981 to 1992 . The majority of patients without MS were older; $74 \%$ above the age of 60 years. The diagnosis of multiple sclerosis was made according to accepted clinical, cerebrospinal fluid, and neuroimaging criteria. The distribution of trigeminal pain treated during these 55 procedures included: $V_{1}(n=2), V_{1-2}(n=5), V_{1.3}(n=5), V_{2}(n$ $=10), V_{2-3}(n=24)$, and $V_{3}(n=9)$. Seven patients had bilateral pain. ${ }^{6}$

\section{Preoperative Medical Management}

All patients were first treated with carbamazepine. When necessary, patients also were treated with phenytoin and baclofen, 1.7 alone or in conjunction with carbamazepine. Occasional patients also were treated with clonazepam. All patients were referred for surgical intervention if medical therapy either failed to provide pain relief, or if they were intolerant of the medical regimen. The duration of medical therapy was variable, but in the majority of patients, longer than one year. PRGR was selected as the initial surgical procedure in order to reduce the risk of postoperative facial deafferentation.

\section{Surgical Technique}

PRGR is performed with the patient awake but under intravenous sedation. Our current technique includes fentanyl and midazolam. Non-invasive blood pressure monitoring is maintained throughout the procedure. The patient is placed in the supine position on a standard operating room table with the head supported by a cerebellar headrest. A C-arm fluoroscopic image intensifier with image storage capability is used to facilitate needle placement into the trigeminal cistern. The needle entry point is marked $2.5 \mathrm{~cm}$ lateral to the corner of the mouth and directed at a point $2.5 \mathrm{~cm}$ anterior to the external auditory canal and in line with the medial ipsilateral pupil. A 20 gauge spinal needle is inserted along this trajectory using fluoroscopic guidance. In occasional patients, penetration of the foramen ovale is facilitated by the additional administration of an ultra short-acting barbiturate agent. After adequate needle placement is confirmed by fluoroscopy, the stylet is removed to observe cerebrospinal fluid (CSF) flow. With correct needle placement, most patients (90\%) demonstrate free flow of CSF; reduced CSF flow is occasionally observed in patients who have had prior procedures. The patient is then placed in the semi-sitting position and the neck is slightly flexed. Cisternography is performed by injecting 0.1 to $0.35 \mathrm{ml}$ of sterile non-ionic, water-soluble iodine contrast media, using fluoroscopic guidance to determine the cistern volume. Crescentic spread of the contrast lateral to the needle indicates a subtemporal injection. The cistern size is estimated by recording the volume of contrast injected before escape of the agent from the trigeminal cistern into the posterior fossa (usually 0.15 $0.30 \mathrm{ml}$ ). The contrast is evacuated by allowing it to flow out from the needle. For patients with lower distribution trigeminal neuralgia, we remove all the contrast from the cistern by placing the patient temporarily supine with the neck extended. In patients with $V_{\text {, }}$ pain, a small residual amount of contrast is left in place in the floor of the cistern thereby allowing the glycerol to "float" on top of the contrast agent and selectively treat $V_{1}$ fibers. Changing the degree of head flexion is also reported to help with selectivity of the injection. ${ }^{8}$ Although these techniques can be used to confer some selectivity to the procedure, they cannot be relied upon to "spare" individual divisions.
During glycerol injection, the patient is placed into the sitting position, and the appropriate volume (depending on cistern size and divisions affected) of glycerol is injected under fluoroscopic guidance. We mix sterile anhydrous $99 \%$ glycerol with tantalum dust, as a permanent marker of the trigeminal cistern. Permanent marking of the postganglionic nerve facilitates needle placement if a repeat procedure is necessary. After injection, the needle is removed and the patient is transferred to the recovery room, remaining in the sitting position with the head flexed for two hours. Normal activity is permitted after two hours. The patient is discharged from hospital the next morning. Prior medications for trigeminal neuralgia are discontinued gradually on an outpatient basis after discharge. Facial sensation is tested within eight hours of the procedure and at repeat follow-up visits.

In forty-two patients $(79 \%)$ the trigeminal cistern appeared normal as defined by contrast cisternography. Eleven patients (21\%) had an abnormal cistern defined either because of low volume or poor CSF flow.

\section{RESULTS}

\section{Surgical Morbidity}

There was no major morbidity related to glycerol rhizotomy and no mortality. Ten patients $(18.5 \%)$ developed an ipsilateral eruption of herpes simplex perioralis, which occurred on the second or third day after injection. The eruption usually lasted for 10 to 11 days. For patients with a history of prior frequent herpes simplex eruptions, we routinely prescribed prophylactic topical acyclovir at the time of PRGR and for 7 days thereafter.

No patient developed other complications of percutaneous procedures such as keratitis, intracerebral hemorrhage, carotidcavernous fistula, meningitis, or facial infection.

\section{Pain Relief}

When pain relief occurred, it did so immediately in approximately half the patients, or over 1-2 weeks in the other half. Detailed follow-up six months or more (median 36, range 6-122 months) after surgery was available in 49 of 53 patients (92\%). At longest follow-up 29 of these patients (59.2\%) had complete pain relief and required no medications for trigeminal neuralgia. An additional eight patients (16.3\%) achieved pain control in conjunction with reduced medication intake. Twelve patients $(24.4 \%)$ had inadequate pain relief although three initially had complete pain relief lasting 6,24 and 36 months respectively. Nine of these twelve patients with inadequate relief were uncontrolled with medication and required subsequent surgical procedures. These procedures included radiofrequency rhizotomy $(n=3)$, microvascular decompression and nerve section $(n=4)$, radiofrequency rhizotomy and subsequent subtemporal nerve section $(\mathrm{n}=1)$, and radiofrequency rhizotomy followed by microvascular decompression $(n=1)$. Table 1 describes pain control at final analysis.

Sixteen of 53 patients (30\%) required repeat PRGR during the eleven year follow-up interval because of recurrent pain, after an initial good response. The mean time to a second glycerol rhizotomy was 17 months (range, 0.5-36). Eight patients had two procedures, seven patients had three procedures, and one patient had four procedures (all unilateral). Subsequently, nine patients were pain free and seven had poor control. Four of these patients then had other procedures (three had radiofrequency rhizotomies and one had a nerve section). The only 
complication from a repeat rhizotomy was marked facial numbness in the patient that had four procedures.

\section{Trigeminal Sensory Changes}

Table 2 indicates the number of patients with reduced trigeminal sensory function after PRGR for 45 evaluable patients, tested from 6 to 122 months after surgery (usually at one or two year intervals). In patients evaluated by questionnaire, a descriptive assessment of facial numbness was used. Twenty-seven patients $(60 \%)$ continued to have normal facial sensation after glycerol rhizotomy. No patient developed deafferentation pain. Onset of moderate or severe facial sensory loss was not followed by recovery of sensation.

\section{Discussion}

Trigeminal neuralgia associated with multiple sclerosis may develop because of demyelinating plaques within the trigeminal nerve root entry zone, nuclei or tracts. ${ }^{9.12}$ In some patients, medication therapies alone prove useful for pain control. For those patients who eventually either develop pain refractory to medical therapy or develop intolerable side effects, various potentially neuroablative procedures (e.g., radiofrequency lesion, PRGR, balloon compression) may prove beneficial. We advocate PRGR as the initial procedure, because of the reduced chance for postoperative trigeminal sensory loss and associated deafferentation pain. As an alternative to radiofrequency rhizotomy, PRGR is a simple, anatomic operation that does not require physiologic localization since patient interaction during the procedure is not necessary. PRGR can be performed with the patient under sufficient sedation for pain control during needle placement. Our initial results reflect accurate intracisternal needle placement confirmed by contrast cisternography.

Golfinos and Shetter reported the results in 12 patients with multiple sclerosis of 309 patients who had a rhizotomy for

Table 1. Relief of Trigeminal Neuralgia after Glycerol Rhizotomy in Patients with Multiple Sclerosis $(n=49)$.

\begin{tabular}{cc}
\hline Pain Control & Number of Patients (\%) \\
\hline Excellent $^{1}$ & $29(59 \%)$ \\
Good $^{2}$ & $8(16 \%)$ \\
Poor $^{3}$ & $12(25 \%)$ \\
\hline & Total 49(100\%) \\
\hline
\end{tabular}

\footnotetext{
I no medication required

2 pain controlled with tolerable oral medication

3 inadequate pain control despite medication
}

Table 2. Facial Numbness after Glycerol Rhizotomy in Patients with Multiple Sclerosis $(n=45)$.

\begin{tabular}{cc}
\hline Numbness & Number of Patients (\%) \\
\hline None & $27(60 \%)$ \\
Mild & $12(27 \%)$ \\
Moderate & $5(11 \%)$ \\
Severe & $1^{*}(2 \%)$ \\
\hline & Total $=45(100 \%)$ \\
\hline * patient had 4 glycerol rhizotomies & \\
\hline
\end{tabular}

trigeminal neuralgia. To treat these 12 patients, 17 glycerol rhizotomies and nine radiofrequency lesions were administered. In both procedures, the mean interval to recurrence of pain was 22 months. Three patients had mild facial numbness; two of these had received a radiofrequency lesion. ${ }^{13}$ Brisman reported results in 16 patients with trigeminal neuralgia and multiple sclerosis using radiofrequency rhizotomy alone $(n=10)$, or with simultaneous radiofrequency rhizotomy and administration of glycerol $(n=6)$. The author found no significant difference in the probability of, or time to recurrence of pain after rhizotomy in patients with and without multiple sclerosis. ${ }^{6}$ The author did not report the degree of pain relief or paresthesia associated with rhizotomy. Brett et al., reported eight patients who had radiofrequency rhizotomy for trigeminal neuralgia and multiple sclerosis with an average follow-up of 26 months. Only one of eight patients had recurrent pain within that follow-up interval. ${ }^{14}$ Latchaw and colleagues stratified their results for pain relief after radiofrequency rhizotomy (96 patients; 5 with multiple sclerosis) according to degree of induced facial numbness. ${ }^{15}$ Patients who acquired a dense sensory deficit had a reduced risk of pain recurrence. This association does not hold for glycerol rhizotomy. In patients with or without demyelinating disease, facial numbness is uncommon after PRGR. Sensory loss can be related to the volume of glycerol injected, especially when the volume exceeds the measured cisternal volume. Of our 18 patients who developed some facial numbness, 9 had had one rhizotomy, and 9 had had multiple procedures. In our experience, facial numbness produced by or increased with multiple glycerol rhizotomies, did not correlate with longer-term pain relief. Burchiel, however, reported in his series of 60 patients (with or without MS) that the duration of pain relief correlated with reduction in facial sensation. ${ }^{16}$ This has not been observed in our overall PRGR experience with over 600 procedures. ${ }^{17}$ Slettebo et al. evaluated 60 patients after PRGR and found no statistically significant variable that predicted recurrence of pain, including facial sensory loss. ${ }^{18}$

Brown and colleagues reported the results on fifty patients who had percutaneous trigeminal nerve balloon compression, five of whom had multiple sclerosis. The overall recurrence rate in their series of 50 patients was $26 \%$ and the mean time until recurrence was 18 months. Their results were not specifically stratified for the multiple sclerosis sub-group. ${ }^{5}$

We compared these results with our overall trigeminal neuralgia series of 480 patients who had 620 glycerol rhizotomies over a 10-year interval. In median follow-up of 3 years, $75 \%$ of patients were pain free, with or without supplemental medication, and $25 \%$ were controlled poorly. ${ }^{17}$ These results compare similarly to the multiple sclerosis subgroup.

Multiple sclerosis-related trigeminal neuralgia often proves difficult to manage with either medical or surgical approaches. Patients with multiple sclerosis tolerate carbamazepine therapy less well and are more prone to develop unpleasant neurologic symptoms such as dizziness or ataxia. ${ }^{6}$ The advantages of PRGR over other techniques include: a) the reduced chance for corneal or facial sensory loss, b) the procedure can be repeated safely and confers additional benefit on repeat injections, and c) apparent equivalence in efficacy with other procedures.

The mechanism of action of glycerol is not known precisely, although both neurolytic and osmotic effects are hypothesized. As a hyperosmolar dehydrating agent, glycerol probably 
provides a selective clinical effect on abnormally myelinated fibers. ${ }^{19}$ This hypothesis is supported by the observation that in most patients, pain relief is provided and most have little change in facial sensation. Lunsford and colleagues found that intracisternal glycerol increased the average latencies and reduced the average amplitudes of trigeminal brain-stem evoked potentials. ${ }^{19,20}$ Histopathologic examination of the trigeminal nerve disclosed focal demyelination, axonal swelling, endoneurial fibrosis and neuronal loss.

In summary, single or repeated percutaneous glycerol rhizotomy is a safe, well-tolerated, and efficacious procedure for most patients with trigeminal neuralgia related to multiple sclerosis. The development of marked facial hypaesthesia is rare, and usually only observed after multiple rhizotomies. Approximately $60 \%$ of patients with pain refractory to medical therapy achieve complete long-term relief off medications.

\section{REFERENCES}

1. Sweet WH. The treatment of trigeminal neuralgia (tic douloureux). N Engl J Med 1986; 315: 174-177.

2. Jannetta PJ. Trigeminal neuralgia: treatment by microvascular decompression. In: Wilkins R, Rengachary SS, eds. Neurosurgery. New York: McGraw-Hill, 1985; 2357-2363.

3. Lunsford LD. Treatment of tic douloureux by percutaneous retrogasserian glycerol injection. JAMA 1982; 248: 449-453.

4. Moraci A, Buonaiuto C, Punzo A, Parlato C, Amalfi R. Trigeminal neuralgia treated by percutaneous thermocoagulation. Comparative analysis of percutaneous thermocoagulation and other surgical procedures. Neurochirurgia 1992; 35: 48-53.

5. Brown JA, McDaniel MD, Weaver MT. Percutaneous trigeminal nerve compression for treatment of trigeminal neuralgia: results in 50 patients. Neurosurgery $1993 ; 32: 570-573$.

6. Brisman R. Trigeminal neuralgia and multiple sclerosis. Arch Neurol 1987; 44: 379-381.

7. Fromm GH, Terrence CF, Chattha AS. Baclofen in the treatment of trigeminal neuralgia: double-sized study and long-term follow-up. Ann Neurol 1984; 15: 240-244.
8. Bergenheim AT, Hariz MI, Laitinen LV. Selectivity of retrogasserian glycerol rhizotomy in the treatment of trigeminal neuralgia. Stereotact Funct Neurosurg 1991; 56: 159-165.

9. Parker HL. Trigeminal neuralgic pain associated with multiple sclerosis. Brain 1928; 51: 46-62.

10. Jensen TS, Rasmussen P, Reske-Nielsene. Association of trigeminal neuralgia with multiple sclerosis: clinical and pathological features. Acta Neurol Scand 1982; 65: 182-189.

11. Friedman CE. Trigeminal neuralgia in a patient with multiple sclerosis. J Endodont 1989; 15: 379-380.

12. Hutchins LG, Harnesberger HR, Jacobs JM, Apfelbaum RI. Trigeminal neuralgia (tic douloureux): MR imaging assessment. Radiology 1990; 175: 837-841.

13. Golfino JG, Shetter AG. Treatment of trigeminal neuralgia in multiple sclerosis patients using radiofrequency thermal rhizotomy and glycerol rhizotomy. J Neurosurg (abst) 1993; 78: 367.

14. Brett DC, Ferguson GG, Ebers GC, Paty DW. Percutaneous trigeminal rhizotomy: treatment of trigeminal neuralgia secondary to multiple sclerosis. Arch Neurol 1982; 39: 219-221.

15. Latchaw JP, Hardy RW, Forsythe SB, Cook AF. Trigeminal neuralgia treated by radiofrequency coagulation. J Neurosurg 1983; 59: 479-484.

16. Burchiel KJ. Percutaneous retrogasserian glycerol rhizolysis in the management of trigeminal neuralgia. J Neurosurg 1988; 69: 361366.

17. Lunsford LD, Duma CM. Percutaneous retrogasserian glycerol rhizotomy: a ten-year experience. Acta Neurochir (abst) 1992; 117; 97.

18. Slettebo $\mathrm{H}$, Hirschberg $\mathrm{H}$, Lindegaard KF. Long-term results after percutaneous retrogasserian glycerol rhizotomy in patients with trigeminal neuralgia. Acta Neurochir 1993; 122: 231-235.

19. Lunsford LD, Bennett MH, Martinez AJ. Experimental trigeminal glycerol injection: electrophysiologic and morphologic effects. Arch Neurol 1985; 42: 146-149.

20. Bennett MH, Lunsford LD. Percutaneous retrogasserian glycerol rhizotomy for tic douloureux. Part 1: results and implications of trigeminal evoked potential studies. Neurosurgery 1984; 14: $431-435$. 